Revista Brasileira de Agricultura Irrigada v.8, n. 1, p. 64 - 76, 2014

ISSN 1982-7679 (On-line)

Fortaleza, CE, INOVAGRI - http://www.inovagri.org.br

DOI: $10.7127 /$ rbai.v8n100199

Protocolo 199.13 - 21/11/2013 Aprovado em 20/02/2014

\title{
ÍNDICE DE MATURAÇÃO DA CANA-DE-AÇÚCAR FERTIRRIGADA SOBRE DIFERENTES LÂMINAS
}

Lígia Campos de Moura ${ }^{1}$, Nelmício Furtado da Silva ${ }^{2}$, Fernando Nobre Cunha ${ }^{3}$, Fabiano José de Campos Bastos ${ }^{4}$, Juliana Aparecida Célia ${ }^{5}$ Marconi Batista Teixeira ${ }^{6}$

\section{RESUMO}

Objetivou-se com o presente trabalho avaliar o índice de maturação e produção de ATR sob influência de diferentes lâminas de irrigação com e sem efeito da fertirrigação com $\mathrm{N}$ e K combinados no sudoeste do estado de Goiás. O material vegetal foi obtido por corte manual, a partir de uma área cultivada com a variedade RB 85-5453, que apresenta como características principais alto teor de açúcar e precocidade, no Instituto Federal Goiano - Câmpus Rio Verde - GO, nas condições de cana planta. O delineamento experimental utilizado foi o de blocos ao acaso, analisado em esquema fatorial 5 x 2, com quatro repetições. Os tratamentos consistiram em cinco níveis de reposição hídrica $(100,75,50,25$ e $0 \%$ de umidade do solo na capacidade de campo) combinados sem e com aplicação de fertilizante (N e K) via água de irrigação (fertirrigação). Foi realizado o monitoramento do Brix da cana em campo, nas quatro últimas quinzenas que antecedem a colheita, período este onde foi cortado a irrigação do experimento. De acordo com o índice de maturação a cana-de-açúcar irrigada apresentou uma maior concentração de brix no final do ciclo, período que antecede a colheita, promovendo uma maturação mais acelerada que foi mais evidente ainda na cana fertirrigada, correspondendo a valores de antecipação de ciclo de até 15 dias para lâmina $100 \%$ irrigada e 30 dias para 50 e $75 \%$ fertirrigada.

Palavras chaves: brix, cana planta, irrigação, qualidade, colheita

\section{MATURATION INDEX SUGAR CANE FERTIRRIGATED UNDER DIFFERENT BLADES}

\footnotetext{
${ }^{1}$ Graduanda em Engenharia de Alimentos, IFGoiano - Câmpus Rio Verde, Rodovia Sul Goiana, Km 01, CEP: 75.901-170, Rio Verde - GO, e-mail: ligialirios@ hotmail.com,

2 Mestrando em Ciências Agrárias - Agronomia, IFGoiano - Câmpus Rio Verde, e-mail: nelmiciofurtado@gmail.com

3 Mestrando em Ciências Agrárias - Agronomia, IFGoiano - Câmpus Rio Verde, e-mail: fernandonobrecunha@hotmail.com

4 Mestrando em Ciências Agrárias - Agronomia, IFGoiano - Câmpus Rio Verde, e-mail: fabianojcbastos@gmail.com

5 Graduanda em Engenharia de Alimentos, IFGoiano - Câmpus Rio Verde, e-mail: josejoaquimcarvalho@yahoo.com.br

${ }^{6}$ Eng. Agrônomo, Prof. Dr. em Agronomia, IFGoiano - Câmpus Rio Verde, e-mail: marconibt@gmail.com
} 


\begin{abstract}
This work aimed to evaluate maturation rate and production of ATR under influence of different blades of irrigation with and without effect of fertirrigation with $\mathrm{N}$ and $\mathrm{K}$ combined in the southwest of the state of Goiás. The plant material was obtained by manual cutting, from a cultivated area with variety RB 85-5453, which presents as main characteristics high sugar content and precocity, in Federal Institute Goiano - Rio Verde - GO, in conditions of plant cane. The experimental design used was the randomized blocks fully randomized $5 \times 2$ factorial design with four repetitions The treatments consisted of five levels of hydration (100, $75,50,25$ and $0 \%$ of soil moisture at field capacity) combined with and without application of $\mathrm{N}$ and $\mathrm{K}$ way irrigation water (fertirrigation). It was carried out the monitoring of the brix of cane in the field, in the last four fortnights before harvest period, was cut irrigation the experiment. In accordance with the rate of maturation of sugar cane irrigated presented a higher concentration of brix at end the cycle, period before harvest, Promoting a more accelerated maturation that was more evident still in the cane fertirrigated, corresponding to values of anticipation of cycle of up to 15 days for blade $100 \%$ irrigated and 30 days for 50 and $75 \%$ fertirrigated.
\end{abstract}

Keywords: brix, plant cane, monitoring, quality, harvest.

\section{INTRODUÇÃO}

O processo de maturação da cana-deaçúcar é um processo fundamental para a indústria, pois a indústria necessita de escalonar seus plantios e períodos de colheita para ter um controle que garanta um fornecimento de matéria-prima durante toda a safra. A região centro oeste não é diferente da sudeste uma vez que a maturação ocorre de maneira natural a partir do final do período chuvoso que corresponde no entorno de abril a maio com a chegada de temperaturas mais baixas, este comportamento ambiental pode afetar em contrapartida a qualidade da cana em função do acumulo de sacarose.

Para Farias (2006), o clima ideal para a cultura da cana-de-açúcar é aquele com temperaturas médias diárias de $30{ }^{\circ} \mathrm{C}$, com fornecimento adequado de água e na estação de maturação e colheita a temperatura deve ser mais baixa, em torno de 10 a $20{ }^{\circ} \mathrm{C}$. Diola \& Santos (2010) afirmam que temperaturas acima de $38^{\circ} \mathrm{C}$ reduzem a fotossíntese e aumentam a respiração e que para o amadurecimento, temperaturas relativamente baixas em uma faixa de 12 a $14^{\circ} \mathrm{C}$ são desejáveis, visto terem influência notável na redução do crescimento vegetativo e elevam o teor de sacarose.

Com o objetivo de aumentar a eficiência da irrigação no cultivo de cana-de-açúcar, Bernardo (2007) afirma ser de extrema importância considerar, na fenologia, os estádios de desenvolvimento da cultura, assim divididos: a germinação e a emergência compreendem o $1^{\circ}$ mês; o perfilhamento e o estabelecimento da 
cultura que têm duração de 2 a 3 meses; o crescimento em biomassa (formação da produção) se estende entre 6 a 7 meses, enquanto a maturação abrange apenas 2 meses. Os dois primeiros estádios são os mais críticos ao déficit hídrico. No terceiro estádio (aumento de biomassa), as plantas respondem à lâmina aplicada, mas o déficit hídrico não causa tantos prejuízos à produtividade quanto nos dois primeiros; no quarto estádio (maturação) é desejável ocorrer déficit hídrico, com reflexos positivos sobre o rendimento de açúcar.

$\mathrm{O}$ nutriente exportado em maior quantidade pela cana-de-açúcar é o potássio pois, além de influenciar na sua qualidade, está envolvido com o mecanismo de abertura $\mathrm{e}$ fechamento do estômato (Felipe, 2008), a ordem de extração de macronutrientes, tanto para a cana-planta como para a cana-soca é: $\mathrm{K}>\mathrm{N}>\mathrm{C}$ a $>\mathrm{Mg}>\mathrm{P}$. Como a falta de nitrogênio é preocupante, o excesso também e indesejável fazendo com que a cana-de-açúcar tenha um crescimento vegetativo excessivo, atrasando a maturação, prejudicando a qualidade da matériaprima pela diminuição do teor de sacarose dos colmos (Rodrigues, 1995).

Dalri et al. (2008), para a variedade RB 72 454, verificaram aumento em ATR de 30.090,20 para 45.597,04 $\mathrm{kg} \mathrm{ha}^{-1}$, entre o obtido em regime de sequeiro e irrigado; esses valores afirmam a importância da irrigação na qualidade da canade-açúcar. Porém a literatura mostra haver resultados que não comprovam o efeito dessa falta de resposta da cana-de-açúcar aos índices tecnológicos à adubação nitrogenada também foi observada por Marcelo (2008); Franco (2008); Franco et al. (2010) e Gouveia Neto, (2012).

Com base na premissa de Bernardo (2007) de que deve se fazer irrigação com o objetivo de aumentar o lucro e a produtividade, em quantidade e em qualidade e além disso, quando se trata do uso da irrigação e fertirrigação na cana-de-açúcar, o comportamento da maturação e dos conteúdo de sacarose se torna mais escasso ainda, principalmente nas condições encontradas em nossas regiões. Farias et al. (2009) obteve resultados com irrigação, que além de aumentar a produtividade da cana-de-açúcar, promoveu melhorias nos índices de qualidade da matériaprima.

Dessa forma, objetivou-se com o presente trabalho avaliar o índice de maturação e produção de ATR sob influência de diferentes lâminas de irrigação com e sem efeito da fertirrigação com N e K combinados no sudoeste do estado de Goiás.

\section{MATERIAL E MÉTODOS}

O material vegetal foi obtido por corte manual, a partir de uma área cultivada com a variedade RB 85-5453, que apresenta como características principais alto teor de açúcar e precocidade, no Instituto Federal Goiano - 
Câmpus Rio Verde - GO, nas condições de cana planta, com plantio em março de 2011, localizada na latitude $17^{\circ} 48^{\prime} 28^{\prime \prime S}$ e longitude 5053'57’O, com altitude média de 720 metros e relevo suave ondulado ( $6 \%$ de declividade). $\mathrm{O}$ clima da região foi classificado conforme Köppen, como Aw (tropical), com precipitação nos meses de outubro a maio, e com seca nos meses de junho a setembro (Figura 1).

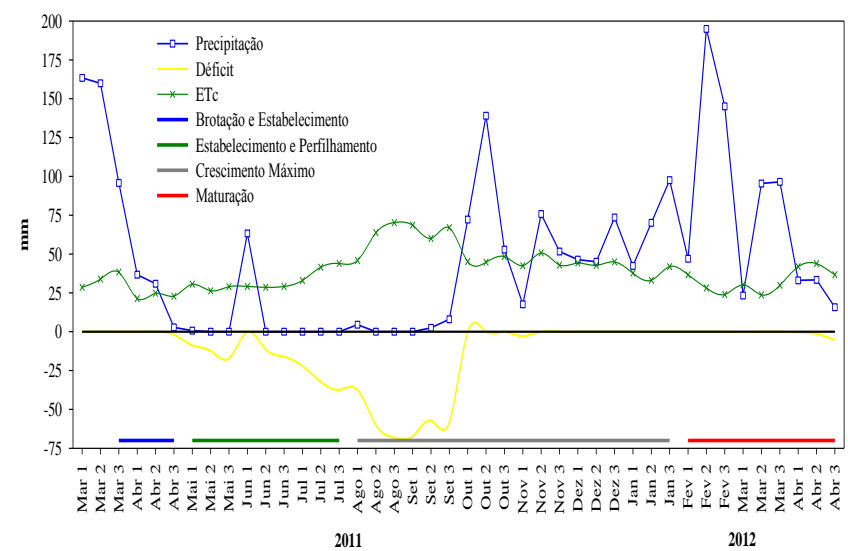

Figura 1. Balanço hídrico decendial do município de Rio Verde no período decorrente do experimento. Fonte: Estação Meteorológica da Fesurv Universidade de Rio Verde.

As parcelas experimentais, constituídas de três sulcos de linha com espaçamento de $1,80 \mathrm{x}$ $0,4 \mathrm{~m}$ entre as linhas e entre linhas duplas e $8 \mathrm{~m}$ de comprimento, totalizando $35,2 \mathrm{~m}^{2}$ de área total por parcela.

O solo da área experimental foi classificado como Latossolo Vermelho distroférrico (LVdf), fase cerrado, de textura média (EMBRAPA, 2006) e as características químicas desse solo encontram-se na (Tabela 1).
Tabela 1. Características químicas do Latossolo Vermelho distroférrico, nas camadas de $0-20$ e $20-40 \mathrm{~cm}$ de profundidade, antes da implantação do experimento.

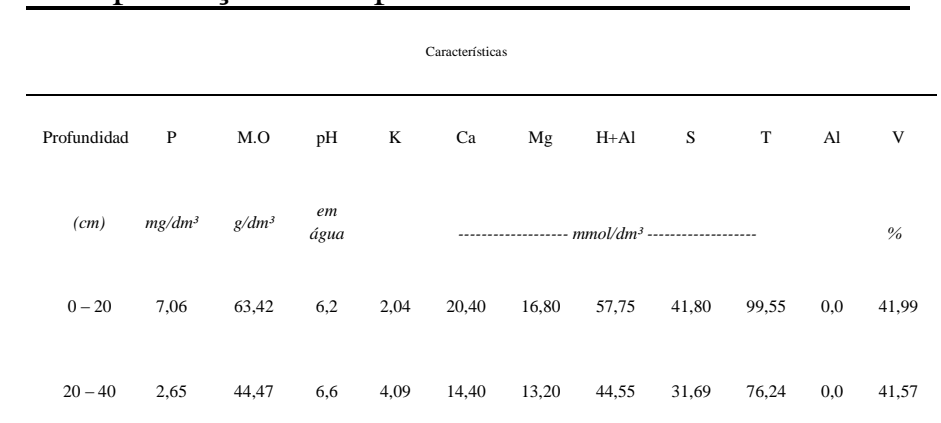

pH em água destilada, g/100 $\mathrm{cm}^{3}$ de terra. Extrator de $\mathrm{P}, \mathrm{K}$ e micronutrientes, Mehlich-1. M.O Matéria Orgânica, $\mathrm{g} / \mathrm{dm}^{3}$. T Capacidade de troca de cátions, $\mathrm{S}+\mathrm{H}+\mathrm{Al}$. V Porcentagem de saturação de bases, V=100 S/T.

O delineamento experimental utilizado foi o de blocos ao acaso, analisado em esquema fatorial $5 \times 2$, com quatro repetições. Os tratamentos consistiram em cinco níveis de reposição hídrica $(100,75,50,25$ e $0 \%$ de umidade do solo na capacidade de campo) combinados sem e com aplicação de fertilizante nitrogenada via água de irrigação (fertirrigação) sendo todas as parcelas dos tratamentos foram adubadas com adubação de base no sulco de plantio, segundo recomendações de Sousa e Lobato (2004). Todos os tratamentos receberam $100 \mathrm{~kg} \mathrm{ha}^{-1}$ de $\mathrm{N}$-uréia, $120 \mathrm{~kg} \mathrm{ha}^{-1}$ de $\mathrm{P}_{2} \mathrm{O}_{5^{-}}$ super simples e $80 \mathrm{~kg} \mathrm{ha}^{-1}$ de $\mathrm{K}_{2} \mathrm{O}$-cloreto de potássio. O fertilizante fosforado foi aplicado no sulco de plantio e o nitrogênio e potássio ao longo do crescimento da cultura por meio do sistema de irrigação de forma que nas parcelas onde não foi prevista a fertirrigação receberam adubação de cobertura com $\mathrm{N}$ a lanço assim como nas fertirrigadas num total de $100 \mathrm{~kg} \mathrm{ha}^{-1}$, 
A Tabela 2, mostra como foi parcelado a fertirrigação com $\mathrm{N}$ e $\mathrm{K}$ durante o ciclo de cultivo.

Tabela 2. Porcentagem do parcelamento de fertirrigação no decorrer do cultivo.

Aplicação

\begin{tabular}{cccccccccccccc}
\hline & $1^{\mathrm{a}}$ & $2^{\mathrm{a}}$ & $3^{\mathrm{a}}$ & $4^{\mathrm{a}}$ & $5^{\mathrm{a}}$ & $6^{\mathrm{a}}$ & $7^{\mathrm{a}}$ & $8^{\mathrm{a}}$ & $9^{\mathrm{a}}$ & $10^{\mathrm{a}}$ & $11^{\mathrm{a}}$ & $12^{\mathrm{a}}$ & Total \\
\hline Mês & $\mathrm{J}$ & & $\mathrm{J}$ & & $\mathrm{A}$ & $\mathrm{S}$ & $\mathrm{O}$ & $\mathrm{N}$ & $\mathrm{D}$ & $\mathrm{J}$ & $\mathrm{F}$ & \\
\hline Potássio* & 2 & 4 & 6 & 8 & & & 10 & & & 100 \\
\hline & & & & & & & & & & & & & \\
\hline
\end{tabular}

*Foi utilizado Cloreto de potássio branco.

Nos tratamentos com reposição hídrica, foi utilizado o método de irrigação por gotejamento subsuperficial. O tubo gotejador foi enterrado a 0,20 $\mathrm{m}$ de profundidade da superfície do solo, no meio da linha dupla, sendo que o mesmo apresenta as seguintes características: modelo Dripnet PC 16150 com parede delgada, pressão de serviço de 1 bar, vazão nominal de $1,0 \mathrm{~L} \mathrm{~h}^{-1} \mathrm{e}$ espaçamento entre gotejadores de $0,50 \mathrm{~m}$.

As aplicações foram realizadas em concentrações iguais para todas as parcelas de forma a aplicar uma quantidade homogenia de nutrientes. A aplicação de $\mathrm{N}$ e $\mathrm{K}$ ocorreram simultaneamente a irrigação, sem a aplicação de diferentes lâminas. Foi utilizado a uréia como fonte de $\mathrm{N}$ e o cloreto de potássio branco como fonte de $\mathrm{K}$. O tempo das fertirrigações eram correspondentes um tempo de 3,5 horas como forma de garantir a oferta de uma mesma quantidade de nutrientes para todos tratamentos. Para injeção dos fertilizantes no sistema de irrigação optou-se por um injetor Venturi que secionava os fertilizantes depois de dissolvidos em uma caixa reservatório com capacidade para $350 \mathrm{~L}$.

$\mathrm{Na}$ aplicação dos fertilizantes via água de irrigação, primeiramente era aplicada somente água para o equilíbrio hidráulico do sistema de irrigação, e permitir maior uniformidade de distribuição dos fertilizantes, em seguida era feito a fertirrigação e ao termino aplicava-se água para lavar o sistema de irrigação.

A irrigação foi conduzida com base em tensiometria digital de punção com sensibilidade de $0,1 \mathrm{kPa}$, sendo as hastes tensiométricas instaladas nas profundidades de $0,20,0,40,0,60$ e $0,80 \mathrm{~m}$ de profundidade e distâncias de 0,15 , $0,30,0,45$ e $0,60 \mathrm{~m}$ do tubo gotejador, com leitura do potencial matricial do solo $(\Psi \mathrm{m})$ registrada diariamente. Para determinar a necessidade de irrigação, utilizou-se tensão crítica de $50 \mathrm{KPa}$. As características físicohídricas do solo foram determinadas mediante a curva de retenção de água no solo, de acordo com Van Genuchten (1980).

Foi realizado o monitoramento do brix da cana em campo, nos dois últimos meses que antecederam a colheita $(45,30,15$ e 0 Dias Antes da Colheita DAC), período este onde foi cortado a irrigação do experimento. Foi determinado o ponto de colheita da cana, utilizando o parâmetro conhecido como Índice 
de Maturação (IM), calculado a partir da divisão do Brix do ápice pelo Brix da base do colmo. O Brix foi determinado em campo, utilizando um refratômetro portátil.

Para a determinações dos parâmetros industriais da cana-de-açúcar foram coletadas 10 colmos de cada repetição totalizando 40 colmos inteiros por tratamento, colhidos aos 385 dias de desenvolvimento das plantas, eliminando somente o ponteiro e as folhas secas, em seguida foram encaminhados para o laboratório pertencente a Usina São Francisco em Quirinópolis - GO.

Foi analisado o parâmetro tecnológico mais utilizado para estimar a qualidade da matéria-prima produzida estão relacionados no Manual de Instruções do Conselho dos Produtores de Cana-de-Açúcar, Açúcar e Álcool do Estado de São Paulo (CONSECANA, 2006). Este manual estabelece e relaciona normas de amostragem e determinações laboratoriais da qualidade da cana-de-açúcar, entre outros parâmetros: Açúcar total recuperável (ATR) ou teor de açúcares totais (glicose, frutose e sacarose), em quilos por tonelada de cana.

Os dados obtidos foram submetidos à análise de variância pelo teste $\mathrm{F}$ ao nível de $1 \mathrm{e}$ $5 \%$ de probabilidade, e em casos de significância dos fatores assim como da interação, foi realizado o desdobramento, foi realizada a análise de regressão e as médias foram comparadas entre si pelo teste Tukey à $5 \%$ de probabilidade, utilizando software Sisvar 5.3 (Ferreira, 2011).

\section{RESULTADOS E DISCUSSÃO}

A disponibilidade hídrica e temperaturas adequadas em 2011 foram favoráveis ao desenvolvimento vegetativo e a menor disponibilidade hídrica, promovida pelo corte da irrigação, favoreceu o processo de maturação natural das plantas de cana-de-açúcar no período da colheita.

O Brix A, aos 45 Dias Antes da Colheita (DAC), demonstrou uma acentuada diferença quando na ausência de irrigação entre sem e com fertirrigação, sendo está de $6,12 \%$, enquanto que nas lâminas de 25, 75 e 100\%, essas diferenças não passaram de $3,1 \%$, aproximadamente duas vezes menor do que a lâmina de $0 \%$; já na lâmina de $50 \%$ não foi observado diferença.

O Brix B na mesma época, apresentou resultados superiores em relação ao Brix A, isto ocorreu na lâmina de 25 e $75 \%$, que não foram diferentes e na lâmina de $50 \%$ que passou a apresentar diferença entre com e sem fertirrigação; também foi verificado uma inversão no que diz respeito as maiores média ocorrida na lâmina de $100 \%$ (Sem > Com).

O índice de maturação (IM), foi de 
maneira geral aos 45 DAC maior na presença de fertirrigação nas lâminas de 0, 50, 75 e $100 \%$ e menor na lâmina de $25 \%$, consequentemente os valores de IM aproximam-se mais rapidamente de 1 quando sob fertirrigação.

As lâminas de 25 e $75 \%$ aos 30 DAC não apresentaram diferença para o Brix A, mas em contraposição demonstraram diferença significativa para o Brix $\mathrm{B}$, sendo que para este, grande parte dos maiores valores foram encontrados sem fertirrigação. Os valores de Brix A e B, com e sem fertirrigação foram concordantes apenas para as lâminas de 0,50 e $100 \%$, os quais apresentaram diferença significativa para 0, 100 (Sem > Com) e 50\% (Sem < Com). O IM médio sem fertirrigação foi de 0,88 enquanto que com fertirrigação este foi de 0,93 (30 DAC); verificou-se diferença significativa no IM a partir da lâmina de $25 \%$, pois não houve diferença em sem irrigação quanto ao IM; assim o IM desta demonstrou um acréscimo considerável de 45 para 30 DAC, entorno de 46 e 20 sem e com fertirrigação respectivamente.

O Brix A foi maior aos 15 DAC nas lâminas de 0 e $50 \%$ e menor nas lâminas de 75 e $100 \%$ (com fertirrigação); para a lâmina de $25 \%$ não foi observada diferença tanto para o Brix A quanto para o Brix B; apenas na ausência de irrigação obteve-se uma desconformidade entre o
Brix A (significativamente diferente) e o Brix B que não apresentou diferença.

A lâmina de 100\% (com fertirrigação) atingiu o ponto de maturação aos 15 DAC, o mesmo não foi verificado, onde somente foi realizada a irrigação. O IM na lâmina de $25 \%$ não apresentou diferença significativa, conforme observado no Brix A e B; para a lâmina de 0 e 75\% com fertirrigação, as quais onde obtiveramse os melhores valores, já a lâmina de $50 \%$ foi a única que sem fertirrigação mostrou-se melhor.

As lâminas de 25 e $100 \%$ na última avaliação foram as que apresentaram maiores valores de Brix A (sem fertirrigação), e as lâminas de 0,50 e 75\% foram superiores quando com fertirrigação. O Brix B indicou uma estabilização e consequentemente não foi observado diferença significativa entre com e sem fertirrigação. O ponto de maturação de maneira geral foi atingido na presença e na ausência de fertirrigação (Tabela 3).

Farias et al. (2009) observaram aumento de 0,72 Brix por incremento de $100 \mathrm{~mm}$ na lâmina de irrigação aplicada; nas condições da pesquisa, o teor mínimo de Brix é de 12,035, e nos tratamentos de sequeiro, em que a precipitação efetiva foi de 780,06 mm (Brix $=17,65 \%)$ e de $100 \%$ da ETc, com lâmina total aplicada de $1.221,08 \mathrm{~mm}($ Brix $=20,83 \%)$, ocorreu um acréscimo de 18,02\% nos sólidos solúveis totais. 
Tabela 3. Brix do Ápice - Brix A; Brix da Base - Brix B; Índice de Maturação - IM com 45, 30, 15 e 0 DAC, para a cana-de-açúcar fertirrigada sob diferentes lâminas de reposição hídrica.

\begin{tabular}{|c|c|c|c|c|c|c|}
\hline \multirow{2}{*}{$\begin{array}{l}\text { Lâmina } \\
(\%)\end{array}$} & \multicolumn{2}{|c|}{ Brix A } & \multicolumn{2}{|c|}{ Brix B } & \multicolumn{2}{|c|}{ IM } \\
\hline & Sem & Com & Sem & Com & Sem & Com \\
\hline & \multicolumn{6}{|c|}{$45 \mathrm{DAC}$} \\
\hline 0 & $7,40 \quad b$ & $13,52 \mathrm{a}$ & $16,35 \mathrm{~b}$ & $18,40 \mathrm{a}$ & $0,45 \mathrm{~b}$ & $0,73 \mathrm{a}$ \\
\hline 25 & $18,45 \mathrm{a}$ & $15,35 \mathrm{~b}$ & $19,52 \mathrm{a}$ & $19,27 \mathrm{a}$ & $0,94 \mathrm{a}$ & $0,80 \mathrm{~b}$ \\
\hline 50 & $16,37 \mathrm{a}$ & $16,62 \mathrm{a}$ & $19,37 \mathrm{~b}$ & $18,57 \mathrm{a}$ & $0,84 \mathrm{~b}$ & $0,90 \mathrm{a}$ \\
\hline 75 & $15,27 \mathrm{a}$ & $16,50 \mathrm{~b}$ & $18,37 \mathrm{a}$ & $18,50 \mathrm{a}$ & $0,83 \mathrm{~b}$ & $0,89 \mathrm{a}$ \\
\hline \multirow[t]{2}{*}{100} & $13,52 \mathrm{~b}$ & $16,52 \mathrm{a}$ & $19,77 \mathrm{a}$ & $19,15 \mathrm{~b}$ & $0,68 \mathrm{~b}$ & $0,86 \mathrm{a}$ \\
\hline & \multicolumn{6}{|c|}{$30 \mathrm{DAC}$} \\
\hline 0 & $17,42 \mathrm{a}$ & $16,52 \mathrm{~b}$ & $19,17 \mathrm{a}$ & $17,67 \mathrm{~b}$ & $0,91 \mathrm{a}$ & $0,93 \mathrm{a}$ \\
\hline 25 & $15,57 \mathrm{a}$ & $15,85 \mathrm{a}$ & $18,62 \mathrm{a}$ & $16,52 \mathrm{~b}$ & $0,83 \mathrm{~b}$ & $0,96 \mathrm{a}$ \\
\hline 50 & $14,22 \mathrm{~b}$ & $19,60 \mathrm{a}$ & $16,27 \mathrm{~b}$ & $20,80 \mathrm{a}$ & $0,88 \mathrm{~b}$ & $0,94 \mathrm{a}$ \\
\hline 75 & $16,87 \mathrm{a}$ & $16,75 \mathrm{a}$ & $19,57 \mathrm{a}$ & $17,60 \mathrm{~b}$ & $0,86 \mathrm{~b}$ & $0,95 \mathrm{a}$ \\
\hline \multirow[t]{2}{*}{100} & $17,75 \mathrm{a}$ & $16,40 \mathrm{~b}$ & $19,20 \mathrm{a}$ & $18,62 \mathrm{~b}$ & $0,92 \mathrm{a}$ & $0,88 \mathrm{~b}$ \\
\hline & \multicolumn{6}{|c|}{$15 \mathrm{DAC}$} \\
\hline 0 & $16,37 \mathrm{~b}$ & $17,42 \mathrm{a}$ & $19,67 \mathrm{a}$ & $19,52 \mathrm{a}$ & $0,83 \mathrm{~b}$ & $0,89 \mathrm{a}$ \\
\hline 25 & $17,30 \mathrm{a}$ & $17,52 \mathrm{a}$ & $19,32 \mathrm{a}$ & $19,27 \mathrm{a}$ & $0,89 \mathrm{a}$ & $0,91 \mathrm{a}$ \\
\hline 50 & $16,62 \mathrm{~b}$ & $17,72 \mathrm{a}$ & $17,67 \mathrm{~b}$ & $19,65 \mathrm{a}$ & $0,94 \mathrm{a}$ & $0,90 \mathrm{~b}$ \\
\hline 75 & $17,42 \mathrm{a}$ & $16,75 \mathrm{~b}$ & $20,62 \mathrm{a}$ & $17,40 \mathrm{~b}$ & $0,84 \mathrm{~b}$ & $0,96 \mathrm{a}$ \\
\hline \multirow[t]{2}{*}{100} & $18,30 \mathrm{a}$ & $17,72 \mathrm{~b}$ & $18,77 \mathrm{a}$ & $17,30 \mathrm{~b}$ & $0,97 \mathrm{~b}$ & $1,02 \mathrm{a}$ \\
\hline & \multicolumn{6}{|c|}{0 DAC } \\
\hline 0 & $18,69 \mathrm{~b}$ & $19,32 \mathrm{a}$ & $18,92 \mathrm{a}$ & $18,82 \mathrm{a}$ & $0,98 \mathrm{~b}$ & $1,02 \mathrm{a}$ \\
\hline 25 & $18,80 \mathrm{a}$ & $18,45 \mathrm{~b}$ & $18,77 \mathrm{a}$ & $18,65 \mathrm{a}$ & $1,00 \mathrm{a}$ & $0,99 \mathrm{a}$ \\
\hline 50 & $18,00 \mathrm{~b}$ & $19,24 \mathrm{a}$ & $18,80 \mathrm{a}$ & $18,85 \mathrm{a}$ & $0,97 \mathrm{~b}$ & $1,02 \mathrm{a}$ \\
\hline 75 & $18,75 \mathrm{~b}$ & $19,42 \mathrm{a}$ & $18,65 \mathrm{a}$ & $18,82 \mathrm{a}$ & $1,00 \mathrm{~b}$ & $1,03 \mathrm{a}$ \\
\hline 100 & $18,63 \mathrm{a}$ & $18,36 \mathrm{~b}$ & $18,70 \mathrm{a}$ & $18,65 \mathrm{a}$ & $0,99 \mathrm{a}$ & $0,98 \mathrm{a}$ \\
\hline
\end{tabular}

Medias seguidas de mesma letra nas linhas não diferem significativamente entre si segundo teste tukey a 5\% de probabilidade. Sem - ausência de fertirrigação $(\mathrm{N}+\mathrm{K})$; Com - presença de fertirrigação $(\mathrm{N}+\mathrm{K})$.

O Brix A foi sempre maior em todos os DAC, quando foi aplicado a fertirrigação; o Brix $B$ foi maior nos DAC de 30 e 15 (sem fertirrigação) e não foi encontrada diferença significativa nos DAC de 45 e 0 . O IM apresentou diferença em todos os DAC, sendo sempre os valores mais elevados na presença de fertirrigação do que na sua ausência. Para Cesnik \& Miocque, 2004 a cana-de-açúcar, os valores de IM admitidos são: (a) menor que 0,60 para cana verde; (b) entre 0,60 e 0,85 para cana em processo de maturação; (c) entre 0,85 e 1 para cana madura; e (d) maior que 1 para cana em processo de declínio de sacarose.

As lâminas de irrigação, assim bem como a aplicação da fertirrigação, correlaciona-se e logo são determinantes para um melhor desempenho do Brix A e na obtenção de valores mais altos de IM; o que tem grande importância por estar interligado com a qualidade da matéria prima (Tabela 4).

Tabela 4. Brix do Ápice - Brix A; Brix da Base - Brix B; Índice de Maturação - IM com 45, 30, 15 e 0 DAC, para a cana-de-açúcar fertirrigada sob diferentes lâminas de reposição hídrica.

\begin{tabular}{|c|c|c|}
\hline Parâmetro & Sem & Com \\
\hline \multicolumn{3}{|c|}{$45 \mathrm{DAC}$} \\
\hline Brix A & $14,20 \mathrm{~b}$ & $15,70 \mathrm{a}$ \\
\hline Brix B & $18,68 \mathrm{a}$ & $18,78 \mathrm{a}$ \\
\hline IM & $0,750 \mathrm{~b}$ & $0,840 \mathrm{a}$ \\
\hline \multicolumn{3}{|c|}{$30 \mathrm{DAC}$} \\
\hline Brix A & $16,37 \mathrm{~b}$ & $17,02 \mathrm{a}$ \\
\hline Brix B & $18,57 \mathrm{a}$ & $18,24 \mathrm{~b}$ \\
\hline IM & $0,880 \mathrm{~b}$ & $0,930 \mathrm{a}$ \\
\hline \multicolumn{3}{|c|}{$15 \mathrm{DAC}$} \\
\hline Brix A & $17,20 \mathrm{~b}$ & $17,43 \mathrm{a}$ \\
\hline Brix B & $19,21 \mathrm{a}$ & $18,63 \mathrm{~b}$ \\
\hline IM & $0,90 \quad b$ & $0,940 \mathrm{a}$ \\
\hline \multicolumn{3}{|c|}{$0 \mathrm{DAC}$} \\
\hline Brix A & $18,57 \mathrm{~b}$ & $18,96 \mathrm{a}$ \\
\hline Brix B & $18,77 \mathrm{a}$ & $18,76 \mathrm{a}$ \\
\hline IM & $0,990 \mathrm{~b}$ & $1,010 \mathrm{a}$ \\
\hline
\end{tabular}

Medias seguidas de mesma letra nas linhas não diferem significativamente entre si segundo teste tukey a $5 \%$ de probabilidade. Sem - ausência de fertirrigação $(\mathrm{N}+\mathrm{K})$; Com - presença de fertirrigação $(\mathrm{N}+\mathrm{K})$.

O ATR na lâmina de $100 \%$, não evidenciou diferença significativa em referência à sem e com fertirrigação. $\mathrm{Na}$ presença de fertirrigação o ATR nas lâminas de 0, 50 e $75 \%$ exibiu aumentos da ordem de 2,35, 6,47 e $5,37 \%$, respectivamente; ao passo que na lâmina de $25 \%$ foi observado uma diminuição de $2,89 \%$.

O ATR quando comparado restritamente sem e com fertirrigação evidenciou um acréscimo de 2,4\%, indicando que tanto a irrigação quanto a fertirrigação tem efeito positivo sobre essa variável (Tabela 5). 
Tabela 5. Cana-de-açúcar fertirrigada sob diferentes lâminas de reposição hídrica.

\begin{tabular}{ccc}
\hline Lâminas $(\%)$ & Sem & Com \\
\hline 0 & $143,92 \mathrm{~b}$ & $147,38 \mathrm{a}$ \\
25 & $144,61 \mathrm{a}$ & $140,55 \mathrm{~b}$ \\
50 & $135,97 \mathrm{~b}$ & $145,38 \mathrm{a}$ \\
75 & $142,77 \mathrm{~b}$ & $150,87 \mathrm{a}$ \\
100 & $136,99 \mathrm{a}$ & $137,39 \mathrm{a}$ \\
\hline Geral & $140,85 \mathrm{~b}$ & $144,31 \mathrm{a}$ \\
\hline
\end{tabular}

Medias seguidas de mesma letra nas linhas não diferem significativamente entre si segundo teste tukey a $5 \%$ de probabilidade. Sem - ausência de fertirrigação $(\mathrm{N}+\mathrm{K})$; Com - presença de fertirrigação $(\mathrm{N}+\mathrm{K})$.

O valor mínimo do Brix A em relação aos DAC, foi verificado aos 45 DAC, o qual foi de 7,4 na ausência da irrigação e da fertirrigação, quando sob irrigação a crescimento máximo verificado foi obtido na lâmina de $25 \%(18,4)$, sendo este $59,1 \%$ superior ao valor mínimo.

$\mathrm{O}$ Brix A e o Brix $\mathrm{B}$ quando sob fertirrigação apresenta uma menor variação aos 45 DAC; aos 30 DAC ambos revelaram uma variação mais acentuada e curvas inversas, com valores máximos do Brix A na lâmina de 50\% $(19,6)$ com fertirrigação e com valor máximo equivalente em sem fertirrigação na lâmina de $75 \%$.

O IM aos 45 DAC, sem fertirrigação foi mais instável do que com fertirrigação, por apresentar decréscimos médios de 59,6\% nas extremidades ou seja nas lâminas de 0 e 100\%; aos 30 DAC as curvas foram inversas com pontos mínimos e máximos nas lâminas de $25 \mathrm{e}$ $75 \%$, sem e com fertirrigação e valores estimados de IM de 1 e 0,83 respectivamente (Figura 2).
A Irrigado (I)

Fertirrigado $(\mathrm{F})$
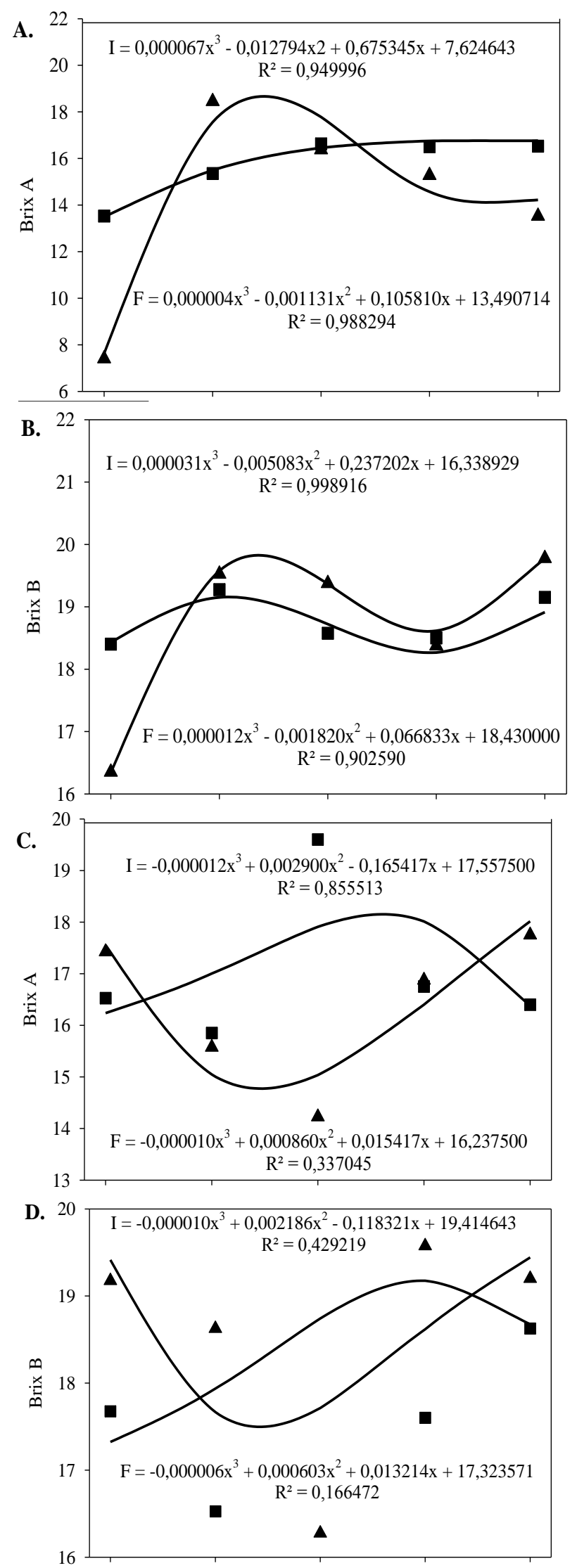

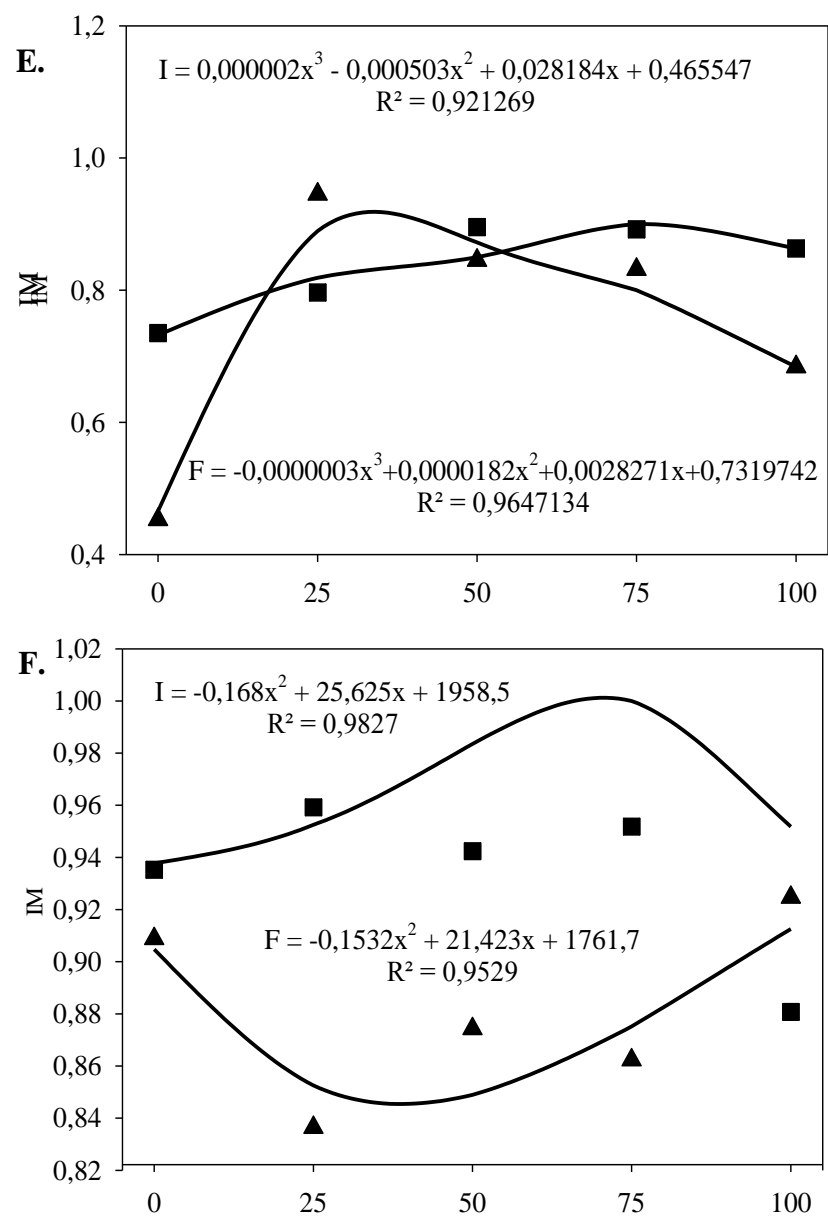

Reposição Hídrica (\%)

Figura 2. (A) Brix do Ápice - Brix A; (B) Brix da Base - Brix B com 30 DAC; (C) Brix do Ápice Brix A; (D) Brix da Base - Brix B com 0 DAC; (E) Índice de Maturação - IM com 30 DAC; (F) Índice de Maturação - IM com 0 DAC, para a cana-deaçúcar fertirrigada sob diferentes lâminas de reposição hídrica.

As curvas do Brix A com e sem fertirrigação se interceptam na lâmina de $68 \%$, mostrando um valor de 17 aos 15 DAC, enquanto que aos 0 DAC a maioria dos valores de com fertirrigação foram superiores aos sem fetirrigação apresentando assim curvas inversas com pontos máximos e mínimos localizado próximo a lâmina central (50\%) sendo essa diferença entre os pontos extremos de 1,24.

O Brix B aos 15 DAC, por apresentar valores próximos, nas lâminas de 0 e 25 seguido de valores diferentes significativamente nas lâminas de 50 (sem < com), 75 e 100\% (sem > com) apresentou duas intersecções nas lâminas de 0 e $50 \%$ e valores estes de Brix $\mathrm{B}$ iguais a 19,5 e 19 respectivamente; também aos 0 DAC foram verificadas duas intersecções nas lâminas de 50 e $87 \%$, valores estes de Brix $\mathrm{B}$ iguais a 18,7 e 18,6 .

O IM aos 15 DAC, de maneira geral aumentou conforme foi aumentando a lâmina de irrigação (com fertirrigação), o mesmo só não pode ser observado na lâmina de $75 \%$ para sem fertirrigado, que exibiu uma diminuição de 10,64\% em relação a lâmina de 50\%; aos 0 DAC sem fertirrigação, demonstrou uma curva mais suave sendo entrelaçada pela curva obtida sob fertirrigação evidenciando ou confirmando o alto impacto da fertirrigação no Brix e $\log o$ no IM (Figura 3).

Estudos desenvolvidos por Oliveira et al. (2011), no município de Carpina, PE, com 11 variedades de cana-açúcar em dois regimes hídricos (sequeiro e irrigado), a irrigação diminuiu o Brix e o ATR não foi modificado com a irrigação.
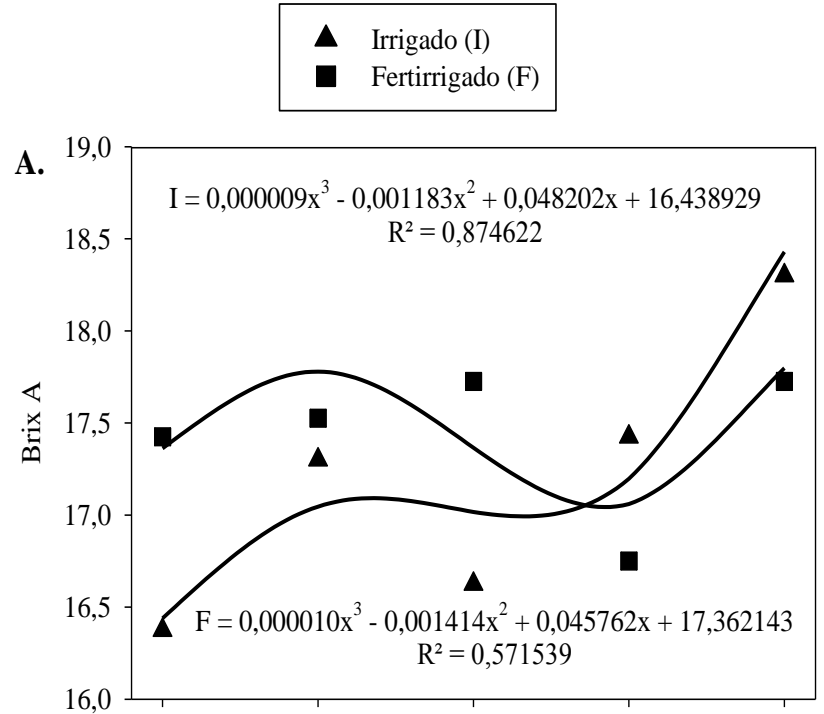

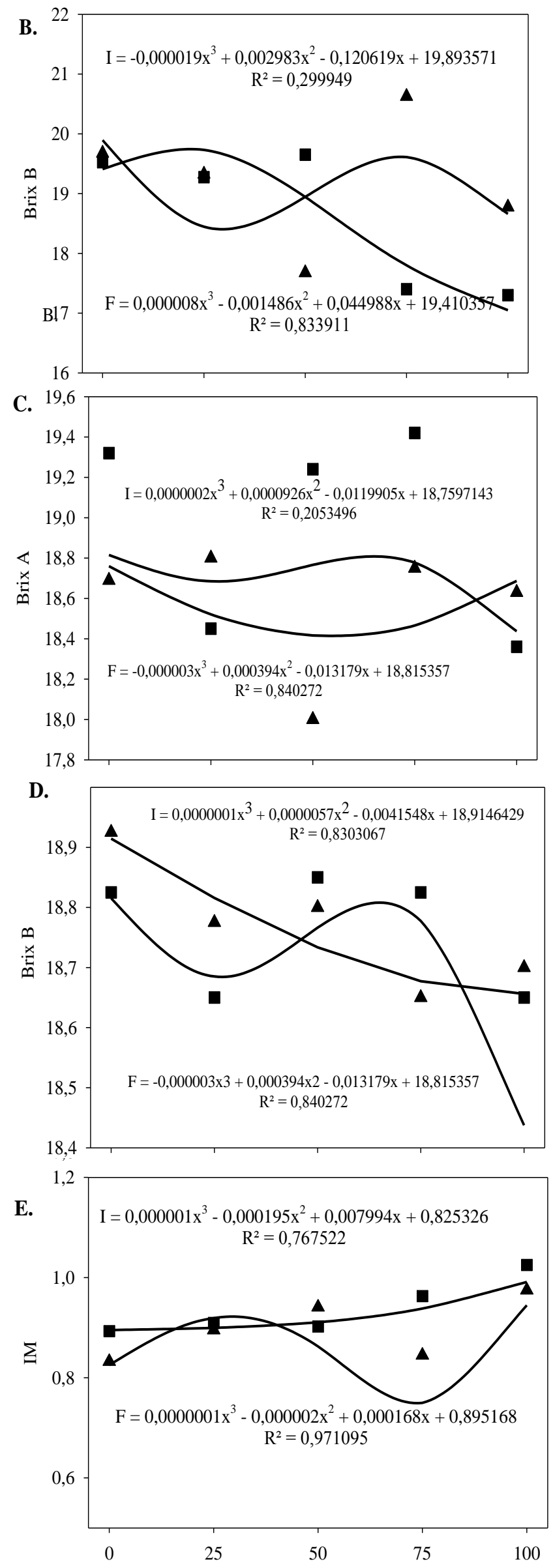

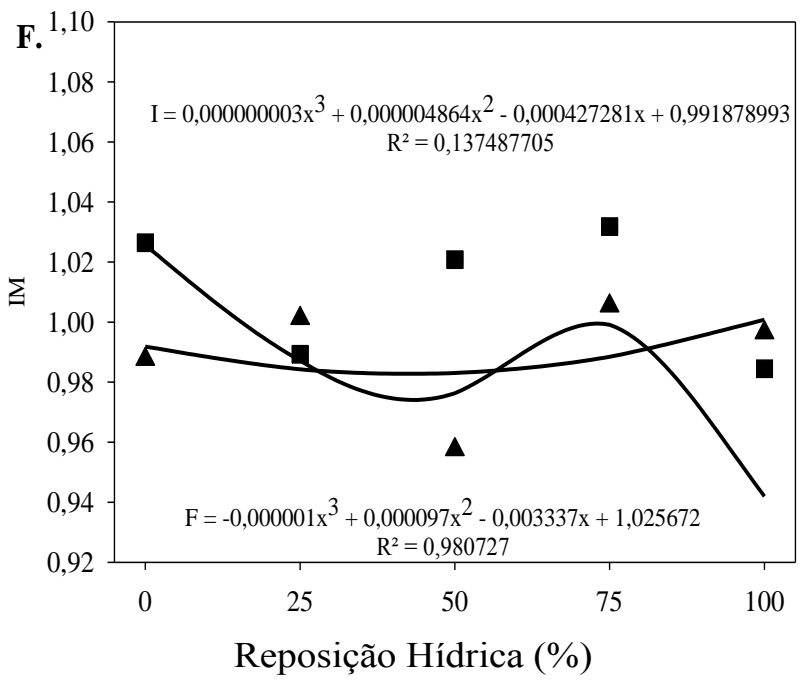

Figura 3. (A) Brix do Ápice - Brix A; (B) Brix da Base - Brix B com 30 DAC; (C) Brix do Ápice Brix A; (D) Brix da Base - Brix B com 0 DAC; (E) Índice de Maturação - IM com 30 DAC; (F) Índice de Maturação - IM com 0 DAC, para a cana-deaçúcar fertirrigada sob diferentes lâminas de reposição hídrica.

O valor máximo de ATR foi observado na lâmina de $75 \%$ com fertirrigação, sendo este de aproximadamente $151 \mathrm{Kg}$ ton cana ${ }^{-1}$, indicando uma forte progressão no ATR devido à fertirrigação principalmente nas lâminas de 50 e $75 \%$; quando aplicado somente a irrigação o ATR não expressou valores mais relevantes, por causa da instabilidade demonstrada pelo ATR quando unicamente sob irrigação, com valores próximos nas lâminas de 0,25 e $75 \%$ e em média igual a $143,8 \mathrm{~kg}$ ton $\mathrm{cana}^{-1}$, assim devido a uma queda de $4,7 \%$ em relação a esta, ocorrida na lâmina de $100 \%$ este adequou-se a um modelo linear decrescente (Figura 4). Farias et al. (2009) estudou-se diferentes lâminas de irrigação e doses de zinco e verificou-se um acréscimo em açúcar com o uso da irrigação em que a diferença em açúcares totais recuperáveis (ATR) da cana-de-açúcar irrigada com $100 \%$ da ETc $\left(147,47 \mathrm{~kg}_{\text {de }}\right.$ ATR $\mathrm{t}^{-1}$ de cana) em referência à 
cana de sequeiro $\left(112,27 \mathrm{~kg}\right.$ de $\mathrm{ATR} \mathrm{t}^{-1}$ de cana) foi de $35,20 \mathrm{~kg}$ de ATR $\mathrm{t}^{-1}$ de cana (queda de $23,87 \%)$.

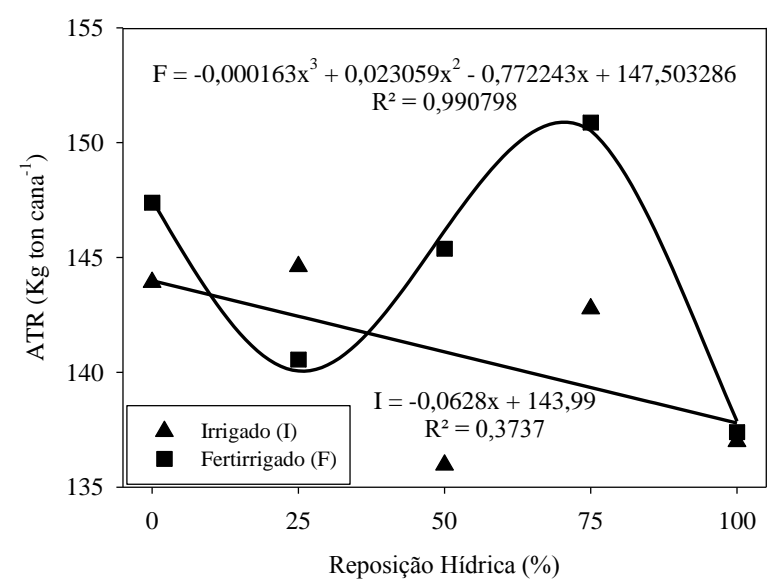

Figura 4. Açúcar total recuperável - ATR ou teor de açúcares totais (glicose, frutose e sacarose), em quilos por tonelada de cana-de-açúcar fertirrigada sob diferentes lâminas de reposição hídrica.

O ponto de colheita ideal está diretamente ligado a uma maior qualidade da cana de açúcar. Durante a fase reprodutivo que se aproxima da maturação a planta de cana de açúcar tende a aumentar a concentração sólidos solúveis da base para o ápice quando esta relação se aproxima de 1 significa que está planta deve ser colhido pois está no seu potencial máximo de acumulo de energia, pois se não colhida esta planta apesar de não apresentar uma homogeneidade de maturação tende a perder qualidade uma vez que na base desta se encontram as maiores concentrações.

\section{AGRADECIMENTOS}

Os autores agradecem ao Ministério da Ciência e Tecnologia (MCT), ao Conselho
Nacional de Desenvolvimento Científico e Tecnológico (CNPq), a Coordenação de Aperfeiçoamento de Pessoal de Nível Superior (CAPES) e à Usina São Francisco (Grupo SJC Bioenergia).

\section{CONCLUSÃO}

A cana-de-açúcar irrigada apresentou uma maior concentração de Brix no final do ciclo, período que antecede a colheita, promovendo uma maturação mais acelerada que foi mais evidente ainda na cana fertirrigada, correspondendo a valores de antecipação de ciclo de até 15 dias para lâmina $100 \%$ irrigada e 30 dias para 50 e $75 \%$ fertirrigada.

$\mathrm{O}$ fornecimento adequado de água durante o ciclo contribuíram para a cana-de-açúcar aumentar sua produtividade de ATR na lâmina de $75 \%$ com uso da fertirrigação com $\mathrm{N}$ e $\mathrm{K}$.

\section{REFERENCIAS BIBLIOGRÁFICAS}

BERNARDO, S. Manejo da irrigação na Cana-de-açúcar. Disponível em: http://www.agronegocio.goias.gov.br/docs/portal /seminarioIII.pdf. Acesso em: 03/11/2007.

CESNIK, R.; MIOCQUE, J. Melhoramento da cana-de-açúcar. Brasília: Embrapa Informação Tecnológica, 2004. 307 p.

CONSECANA - Conselho dos Produtores de Cana-de-açúcar, Açúcar, Álcool do Estado de São Paulo. Manual de instruções. 5.ed. Piracicaba: CONSECANA, 2006. 112p. 
DALRI, A.B.; CRUZ, R.L.; GARCIA, C.J.B. Irrigação por gotejamento subsuperficial na produção e qualidade da cana-de-açúcar. Irriga, Botucatu, v. 13, n. 1, p. 1-11, 2008.

DIOLA, V.; SANTOS, F. Fisiologia. In: SANTOS, F.; BORÉM, A.; CALDAS, C. Canade-açúcar: bioenergia, açúcar e álcool tecnologia e perspectivas. Viçosa: Suprema Gráfica e Editora Ltda., 2010. p. 25 - 49.

EMBRAPA. Centro Nacional de Pesquisa de Solos. Sistema brasileiro de classificação de solos. 2 ed. Brasília: Embrapa Produção de Informação; Rio de Janeiro: Embrapa Solos, 2006.

FARIAS, C.H.A.; FERNANDES, P.D.; GHEYI, H.R.; DANTAS NETO, J. Qualidade industrial de cana-de-açúcar sob irrigação e adubação com zinco, em Tabuleiro Costeiro paraibano. Revista Brasileira de Engenharia Agrícola e Ambiental, Campina Grande, v. 13, n. 4, p. 419428, 2009.

FARIAS. C.H. de A., Otimização do uso da Água e do Zinco na Cana-de-açúcar em Tabuleiro Costeiro Paraibano. 2006. 142p. Tese (Doutorado Temático em Recursos Naturais) - Universidade Federal de Campina Grande, Campina Grande. 2006.

FELIPE, D.C. Produtividade da cana-deaçúcar (Saccharum oficinarum L.) submetida a diferentes épocas de plantio e a adubação mineral. 2008. 69f. Dissertação (Mestrado em Agronomia), Centro de Ciências Agrárias, Universidade Federal da Paraíba, Areia. 2008.

FELIPE, D.C. Produtividade da cana-deaçúcar (Saccharum oficinarum L.) submetida a diferentes épocas de plantio e a adubação mineral. 2008. 69f. Dissertação (Mestrado em Agronomia), Centro de Ciências Agrárias, Universidade Federal da Paraíba, Areia. 2008.
FERREIRA, D. F. Sisvar: a computer statistical analysis system. Ciência e Agrotecnologia (UFLA), v. 35, n.6, p. 1039-1042, 2011.

FRANCO, H.C.J. Eficiência agronômica da adubação nitrogenada pela cana-planta. 2008. 128f. Tese (Doutorado em Agronomia), Universidade de São Paulo, Piracicaba. 2008.

FRANCO, H.C.J.; TRIVELIN, P.C.O.; FARONI, C.E.; VITTI, A.C.; OTTO, R. Stalk yield and technological attributes of planted cane as related to nitrogen fertilization. Scientia Agricola, Piracicaba, v. 67, n. 5, p. 579-590, 2010.

GOUVEIA NETO, C. G. Rendimento agroindustrial da cana-de-açúcar sob suplementação hídrica e parcelamento de nitrogênio. 145p. 2012. Universidade Federal de Campina Grande - Campina Grande, PB. Tese (Doutorado).

OLIVEIRA, E. C. A.; FREIRE, F. J.; OLIVEIRA, A.C.; SIMÕES NETO, D. U.; ROCHA, A.T.; CARVALHO, L. A. Produtividade, eficiência de uso da água e qualidade tecnológica da cana-de-açúcar submetida a diferentes regimes hídricos. Pesquisa Agropecuária Brasileira, Brasília, v. 46, n. 6, p. 617-625, 2011.

RODRIGUES, J. D. Fisiologia da cana-deaçúcar. Instituto de Biociências - Universidade Estadual Paulista, 99p. (Apostila), 1995.

SOUSA, D. M. G.; LOBATO, E. Cerrado: Correção do solo e adubação. 2.ed. Brasília, Embrapa Informação Tecnológica, 416p. 2004.

van GENUCHTEN, M. T. A closed form equation for predicting the hydraulic conductivity of unsaturated soils. Soil Science Society of America Journal, v. 44, p. 892-898, 1980. 